\title{
Epidemiology, Clinical Features, and Use of Early Supportive Measures in PHACE Syndrome: A European Multinational Observational Study
}

Disse, Sigrid Claudia ; Toelle, Sandra P ; Schroeder, Simone ; Theiler, Martin ; Weibel, Lisa ; Broser, Philip ; Langner, Cornelia ; Siegel, Dawn ; Brockmann, Knut ; Schoenfelder, Ines ; Meyer, Sascha

\begin{abstract}
Background: PHACE syndrome is a rare inborn condition characterized by large facial hemangiomas and variable malformations of the arterial system, heart, central nervous system, and eyes. According to Orphanet estimates, the prevalence is $<1.0$ per million. Data from Europe are limited to small case series, and there are no population-based data available. Objectives: We conducted the present study to provide populationbased estimates of the disease prevalence of PHACE syndrome in children in Germany, Switzerland, and Austria. We compared these first systematic data on PHACE syndrome from Europe to published data from the PHACE Syndrome International Clinical Registry and Genetic Repository (USA). Clinical features in our cohort with PHACE syndrome were assessed in detail, including the need for early supportive measures. Methods: We used a population-based approach by means of a previously well-established network of child neurologists from Germany, Switzerland, and Austria ("ESNEK") to identify potential patients. The patients' guardians and child neurologists were asked to fill in questionnaires developed in collaboration with the International PHACE Registry. Results: We identified 19 patients with PHACE syndrome. Estimated prevalence rates were 6.5 per million in Switzerland, 0.59 per million in Germany, and 0.65 per million in Austria. A subset of 10 patients from Germany and Switzerland participated in our study, providing detailed clinical assessment (median age: 2.5 years; 9 females, 1 male). Cerebrovascular involvement was frequent (80\%). Facial hemangioma extent correlated significantly with the number of organs involved $(\mathrm{p}=0.011)$. In 9 out of 10 patients, facial hemangiomas were treated successfully with oral propranolol. Baseline demographic data as well as the rate of cerebrovascular and cardiovascular anomalies were in line with those from the US International PHACE Registry and other published PHACE cohorts. Conclusions: Our study provides population-based estimates for PHACE syndrome in 3 German-speaking countries. The data from Switzerland indicate that PHACE syndrome may be more prevalent than demonstrated by previous reports. Underreporting of PHACE syndrome in Germany and Austria likely accounts for the differences in prevalence rates. The clinical observation of a potential association between the size of facial hemangioma and extent of organ involvement warrants further investigation.
\end{abstract}

DOI: https://doi.org/10.1159/000508187

Posted at the Zurich Open Repository and Archive, University of Zurich

ZORA URL: https://doi.org/10.5167/uzh-188544

Journal Article

Published Version

Originally published at:

Disse, Sigrid Claudia; Toelle, Sandra P; Schroeder, Simone; Theiler, Martin; Weibel, Lisa; Broser, Philip; Langner, Cornelia; Siegel, Dawn; Brockmann, Knut; Schoenfelder, Ines; Meyer, Sascha (2020). Epidemiology, Clinical 
Features, and Use of Early Supportive Measures in PHACE Syndrome: A European Multinational Observational Study. Neuroepidemiology, 54(5):383-391.

DOI: https://doi.org/10.1159/000508187 


\title{
Epidemiology, Clinical Features, and Use of Early Supportive Measures in PHACE Syndrome: A European Multinational Observational Study
}

\author{
Sigrid Claudia Disse ${ }^{a}$ b Sandra P. Toelle ${ }^{c} \quad$ Simone Schroeder ${ }^{d}$ Martin Theiler $^{e}$ \\ Lisa Weibel $^{\text {e }}$ Philip Broser ${ }^{f}$ Cornelia Langner ${ }^{g}$ Dawn Siegel ${ }^{\text {h }}$ \\ Knut Brockmann ${ }^{d}$ Ines Schoenfelder ${ }^{i}$ Sascha Meyer ${ }^{a}$ \\ aDepartment of Neuropediatrics, Children's Hospital at University Medical Center Homburg, Homburg, Germany; \\ ${ }^{b}$ Children's Hospital Weiden, Kliniken Nordoberpfalz AG, Weiden, Germany; 'Department of Neuropediatrics, \\ University Children's Hospital Zurich, Zurich, Switzerland; Interdisciplinary Pediatric Center for Children with \\ Developmental Disabilities and Severe Chronic Disorders, Department of Pediatrics and Adolescent Medicine,

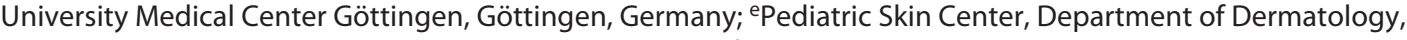 \\ University Children's Hospital Zurich, Zurich, Switzerland; ${ }^{\mathrm{f} C e n t e r ~ f o r ~ P e d i a t r i c ~ N e u r o l o g y, ~ D e v e l o p m e n t ~ a n d ~}$ \\ Rehabilitation, Ostschweizer Kinderspital, St. Gallen, Switzerland; 9Pediatric Practice, Neuropediatrics/Epilepsy,

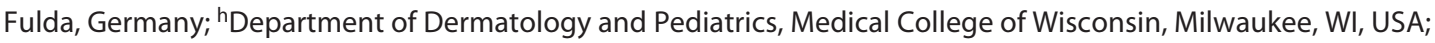 \\ 'Pediatric Practice, Pediatrics and Psychotherapy, Lübben, Germany
}

\section{Keywords}

PHACE syndrome · Hemangioma $\cdot$ Epidemiology .

Multinational study · Population-based study · Prevalence

\begin{abstract}
Background: PHACE syndrome is a rare inborn condition characterized by large facial hemangiomas and variable malformations of the arterial system, heart, central nervous system, and eyes. According to Orphanet estimates, the prevalence is $<1.0$ per million. Data from Europe are limited to small case series, and there are no population-based data available. Objectives: We conducted the present study to provide population-based estimates of the disease prevalence of PHACE syndrome in children in Germany, Switzerland, and Austria. We compared these first systematic data on PHACE syndrome from Europe to published data from the PHACE Syndrome International Clinical Registry and Genetic Repository (USA). Clinical features in our cohort with PHACE
\end{abstract}

\section{KARGER}

(c) 2020 S. Karger AG, Basel

karger@karger.com

www.karger.com/ned syndrome were assessed in detail, including the need for early supportive measures. Methods: We used a populationbased approach by means of a previously well-established network of child neurologists from Germany, Switzerland, and Austria ("ESNEK") to identify potential patients. The patients' guardians and child neurologists were asked to fill in questionnaires developed in collaboration with the International PHACE Registry. Results: We identified 19 patients with PHACE syndrome. Estimated prevalence rates were 6.5 per million in Switzerland, 0.59 per million in Germany, and 0.65 per million in Austria. A subset of 10 patients from Germany and Switzerland participated in our study, providing detailed clinical assessment (median age: 2.5 years; 9 females, 1 male). Cerebrovascular involvement was frequent $(80 \%)$. Facial hemangioma extent correlated significantly with the number of organs involved $(p=0.011)$. In 9 out of 10 patients, facial hemangiomas were treated successfully with oral propranolol. Baseline demographic data as well as the rate of cerebrovascular and cardiovascular anomalies 
were in line with those from the US International PHACE Registry and other published PHACE cohorts. Conclusions: Our study provides population-based estimates for PHACE syndrome in 3 German-speaking countries. The data from Switzerland indicate that PHACE syndrome may be more prevalent than demonstrated by previous reports. Underreporting of PHACE syndrome in Germany and Austria likely accounts for the differences in prevalence rates. The clinical observation of a potential association between the size of facial hemangioma and extent of organ involvement warrants further investigation.

(C) 2020 S. Karger AG, Basel

\section{Introduction}

The acronym PHACE(S) (OMIM 606519) designates a rare, inborn condition comprising malformations of the posterior fossa of the brains $(\mathrm{P})$, large segmental facial hemangiomas $(\mathrm{H})$, and variable involvement of other organs such as anomalies of the arterial system (A), the heart (cor, C), the eyes (E), and sternal defects (S) [1]. Specific patterns of facial hemangioma corresponding to embryonic facial prominences, persistence of embryonic vessels, and arterial anomalies including aberrant course or origin point toward a defect in early embryogenesis [2]. In a study evaluating 108 infants with large segmental facial hemangioma, approximately every third patient was diagnosed with PHACE syndrome [3]. According to Orphanet estimates, the prevalence is $<1 / 1,000,000$ [4]. Yet, population-based data are scarce and, to the best of our knowledge, no studies on the prevalence of PHACE syndrome have been conducted in Europe so far. We used a network of child neurologists to study the epidemiology and clinical features of PHACE syndrome in Germany, Switzerland, and Austria [5].

\section{Materials and Methods}

A Multinational Study in Germany, Switzerland, and Austria

We conducted a multinational survey in the 3 German-speaking countries Germany, Switzerland, and Austria, using a pre-existing network of child neurologists ("ESNEK," i.e., in German "Erhebung Seltener Neurologischer Erkrankungen im Kindesalter"; English translation "Acquisition of Rare Neurological Disorders in Childhood") [5]. ESNEK is a well-established network of child neurologists in the German-speaking countries Germany, Switzerland, and Austria. It is located at University Medical Center Göttingen, Germany. Through the network, all registered child neurologists from Germany, Switzerland, and Austria were contacted by email to recruit potential pediatric patients with the rare neurologic condition under investigation. This mailing list, which is continuously being updated, includes approximately 1,700 email addresses. Among these, 70 addresses each are from Swiss and from Austrian child neurologists, respectively. The child neurologists were asked to send an email response with just the case numbers of patients with PHACE syndrome or Sturge-Weber syndrome (SWS) in their medical attendance, if any. They were not asked to respond if they did not care for any such patients.

Orphanet is a well-established platform and reference source for rare diseases. It is a freely accessible network of 41 countries, coordinated at the INSERM in Paris. The network was founded in France and it is still funded by the INSERM, the French Ministry of Health, and by the European Commission [6]. It provides insights not only on the characteristics of rare diseases itself but also on current research, orphan drugs, patient organizations, expert networks, and diagnostic tests.

For this study, we included all patients with a definitive clinical diagnosis of PHACE syndrome. In a parallel study arm, we simultaneously recruited patients with SWS, that is, a similar, but more well-known phacomatosis, to identify potentially unrecognized/ confounded cases of PHACE syndrome from the SWS cohort. The referring physicians included a broad range of child neurologists, operating in private practices to tertiary referral centers, for example, university hospitals. Among all registered collaboration partners, 11 child neurologists from Germany, Switzerland, and Austria identified suitable patients with PHACE syndrome. One patient was self-reported by his guardians; 2 patients were diagnosed and recruited by SD (one of the 2 latter patients was reported previously [7]).

The study protocol was approved by the responsible Institutional Review Board in Saarbrücken, University of Saarland, Germany (ID: 209/17, October 2017), for all patients. All included patients' legal guardians provided informed consent. The study was registered in the German Clinical Trials Registry (ID: DRKS 00013551, UTN U1111-1206-9923).

\section{Case Definitions and Inclusion Criteria}

As a case definition, we used the international criteria for PHACE syndrome published in 2009 by a multidisciplinary consensus group of physicians [8] with adaption following analysis of a high-risk cohort of pediatric patients with large facial hemangioma [3]. Accordingly, patients aged $<18$ years at time of study inclusion with a large facial hemangioma $>5 \mathrm{~cm}$ in diameter and 1 major criterion or 2 minor criteria were enrolled. Study enrollment started in January 2018 and comprised all pediatric patients with clinically established PHACE syndrome up to December 2018. Cases were only included after clinical diagnosis of PHACE syndrome was confirmed using medical records and/or questionnaires.

\section{Data Assessment and Clinical Variables}

We used 2 different, partially modified, translated, and professionally retranslated versions of a questionnaire developed by the PHACE registry in Wisconsin, USA, to ensure comparability to existing databases (see Appendix for the questionnaires used in this study). The PHACE Syndrome International Clinical Registry and Genetic Repository is a research registry located at Children's Hospital of Wisconsin in the city of Milwaukee, Wisconsin, USA. Patients were enrolled into the registry from November 18, 2010, to August 31, 2016, originating from the USA and Canada [9]. 
Thus, the registry covered a pediatric population of 79.8 million children (as of 2017/2018) [10,11]. So far, 218 patients have been enrolled in the registry [9]. One questionnaire was designed for the patients' families, the other for the patients' child neurologists. While the original questionnaire version for child neurologists included only assessment of PHACE criteria, we added questions on perinatal risk factors, family history, current symptoms, neurologic involvement, and organ involvement as well as questions on therapies and therapeutic success. The family questionnaires included patients' histories and their parents' histories, ethnicity, perinatal factors, descriptions of the phenotype including PHACE criteria, and organ involvement as well as development, feeding, and use of the healthcare system. Furthermore, we asked the families about diagnostic procedures including genetic analyses, current clinical symptoms, surgeries, medication and hemangioma treatment, and need for early supportive measures (physical therapy, occupational therapy, special education services, and speech and language therapy).

\section{Statistical Methods}

We first performed standard descriptive statistics. If normally distributed, we used mean/standard deviation to describe continuous variables and median/interquartile ranges for other distributions. For categorical variables, we indicated absolute and relative frequencies. Exploratory analyses were used to assess potential associations between covariates. The results of descriptive statistics were compared to published data from the International PHACE registry and to other PHACE cohorts. Current data on the pediatric populations from Germany, Switzerland, and Austria were extracted from public electronic databases [12-16]. For calculation of prevalence rates, standard epidemiologic procedures were used. One-year-period prevalence rates for PHACE syndrome in Germany, Switzerland, and Austria in 2018 were calculated, using midyear populations under risk. We used midyear populations because this procedure minimizes error due to changes in the population occurring during the course of 1 year. As the assumptions of independent disease occurrence and homogeneity of risks for the individual patients were fulfilled, we used a binomial distribution to determine confidence intervals of prevalence rates [17]. More specifically, we used the binconf function from the Hmisc package in R 3.5.3 to calculate Wilson score test-based confidence intervals. All analyses were conducted with Microsoft Excel 2013 (descriptive statistics) and R 3.5.3. (data analysis).

\section{Results}

We received notifications of 19 cases with clinically diagnosed PHACE syndrome ( 8 from Germany, 10 from Switzerland, and 1 from Austria). 10 cases consented to participate in our study and completed both the families' and the child neurologists' questionnaires (52.6\%). In all patients, we critically reviewed the detailed questionnaires which included descriptions of facial hemangioma and vascular anomalies as well as all other PHACE criteria to confirm the diagnosis. In $60 \%$, we additionally re-
Table 1. Characteristics of PHACE syndrome patients

\begin{tabular}{lc}
\hline Patient characteristics $(n=10)$ & $N(\%)$ \\
\hline Sex & \\
Male & $1(10)$ \\
Female & $9(90)$ \\
Current age in years & $2.5(1.75) ;$ \\
$\quad$ (median, IQR; range) & 10 months to 9 years \\
Race & \\
Caucasian & $9(90)$ \\
Asian (Turkish) & $1(10)$ \\
Country & \\
Germany & $5(50)$ \\
Austria & $0(0)$ \\
Switzerland & $5(50)$ \\
PHACE(S) criteria & \\
Posterior fossa & $4(40)$ \\
(Facial) Hemangioma & $10(100)$ \\
Arterial (cerebrovascular) anomalies & $8(80)$ \\
Cardiovascular anomalies & $5(50)$ \\
Eye anomalies & $3(30)$ \\
Sternal defect & $1(10)$
\end{tabular}

Absolute and relative frequencies are indicated for categorical variables. For the numerical variable, median, interquartile range, and range are indicated.

ceived copies of medical records including imaging studies and descriptions/photos of facial hemangioma. One of our cases with PHACE syndrome had been confounded previously with SWS, but the diagnosis had been corrected prior to this study.

\section{Patient Characteristics}

All patients fulfilled the current criteria for "definite PHACE syndrome" [3]. At inclusion in our study, the patients' ages were between 10 months and 9 years. All patients were born in Europe and were unrelated. In accordance with previous reports, for example, [18], we included arachnoid cysts as posterior fossa involvement. Patients' characteristics are summarized in Table 1.

\section{Prevalence Rate of PHACE Syndrome in Germany, Switzerland, and Austria}

All prevalence rates were calculated based on the total number of notifications by the collaborating pediatricians, independent of study participation. Overall prevalence rates were $0.59 / \mathrm{million}$ (95\% CI: 0.299-1.164/million) in Germany and 0.65/million (95\% CI: 0.033-3.693/ million) in Austria, but 10-fold higher in Switzerland (6.57/million) (95\% CI: 3.571-12.103/million). 
Table 2. PHACE criteria including MRI characteristics and facial hemangioma localization in this cohort, as well as localization of extra facial hemangioma and development/feeding

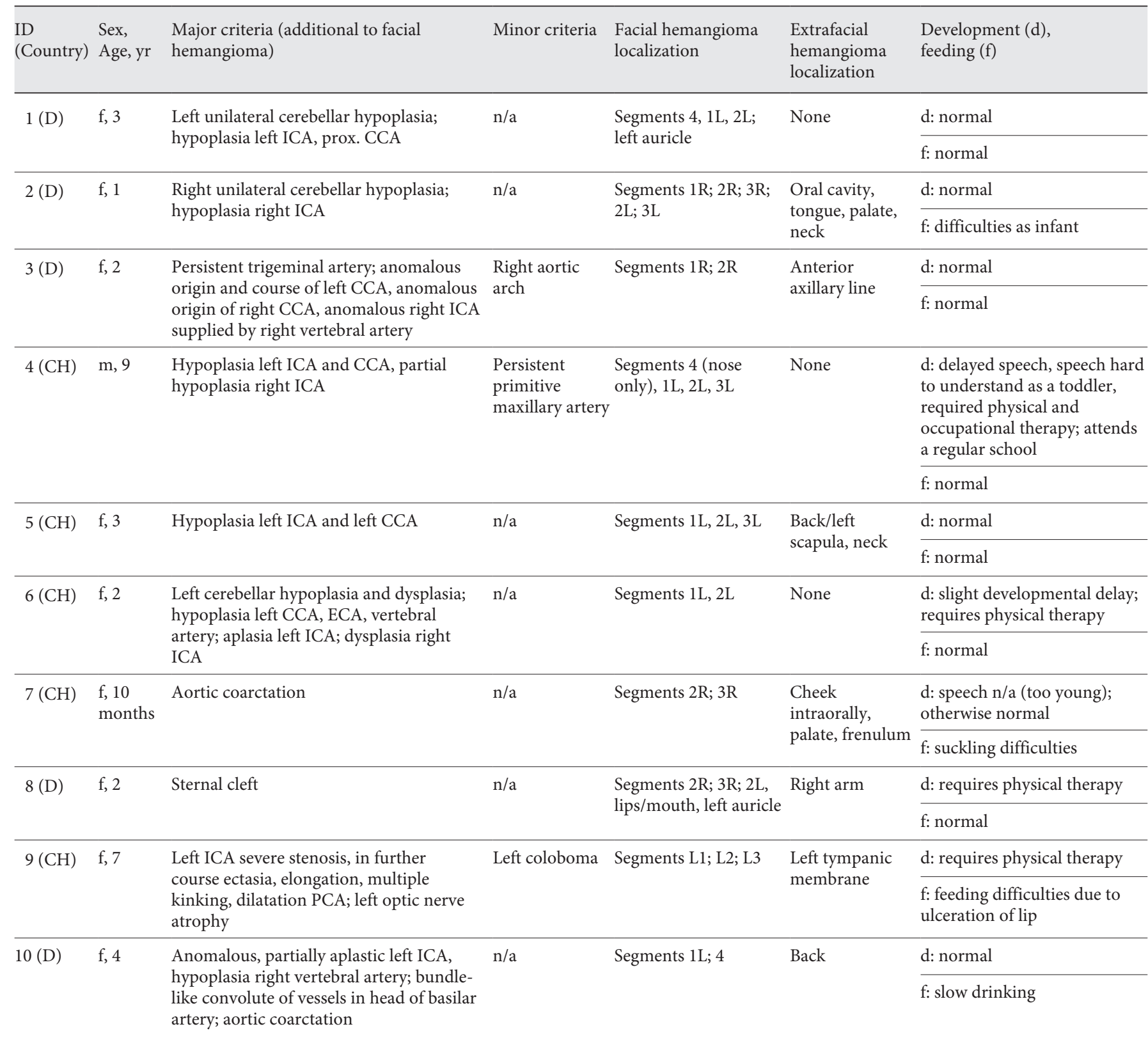

D, Germany; CH, Switzerland; ICA, internal carotid artery; CCA, common carotid artery; ECA, external carotid artery; PCA, posterior cerebral artery.

Due to predominance of younger children $(<5$ years $)$ in the German subcohort, we calculated age-specific prevalence rates for Germany and Switzerland. Swiss agespecific prevalence for children aged $0-5$ years yielded 5.77/million (95\% CI: 1.963-16.975); thus, the age-specific rate showed to be comparable to the overall Swiss prevalence rate. Age-specific prevalence in German children of $0-5$ years of age was significantly higher than the overall prevalence: $1.08 /$ million (95\% CI: 0.462-2.532).

\section{PHACE Criteria in This Patient Cohort}

Table 2 provides an overview of the patients' major and minor criteria for PHACE syndrome [3]. Most patients showed facial hemangioma and at least one cere- 
Fig. 1. Association between number of segments affected by facial hemangioma and number of involved organ systems per patient with PHACE syndrome in this cohort.

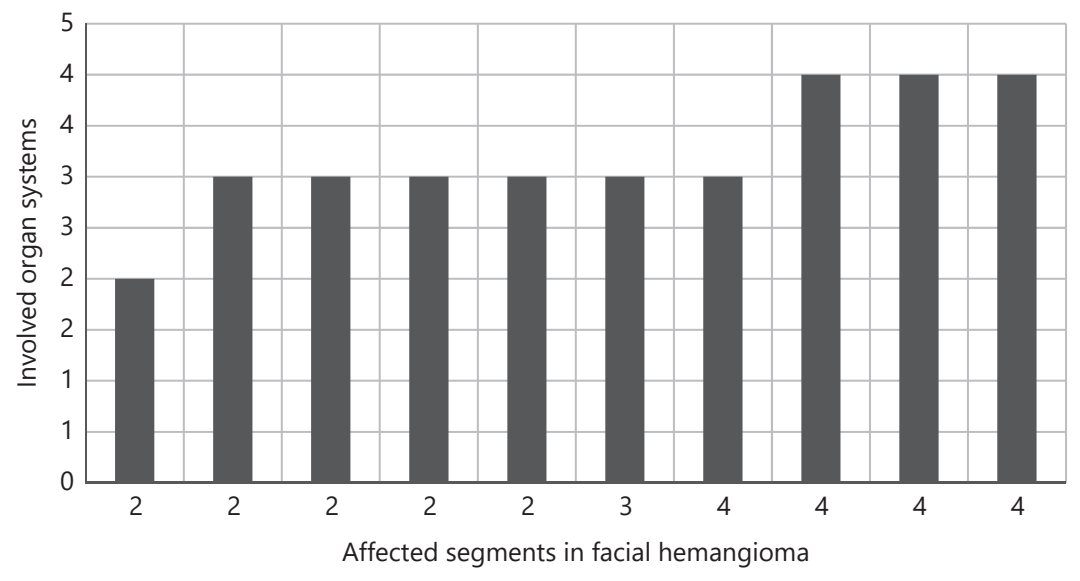

brovascular malformation. Posterior fossa anomalies were recorded in $4 / 10$ cases (40\%). One patient showed a sternal defect and thus can be classified as "PHACES" syndrome.

\section{Facial Hemangioma and Organ Involvement}

Facial hemangioma involved between 2 and 4 of the previously described facial segments. Two patients (20\%) showed bilateral hemangioma (excluding the midline segment 4). Aside of facial hemangioma, 7 patients (70\%) showed an additional extra facial hemangioma (Table 2). Other clinical features were congenital hypothyroidism (due to agenesis of the thyroid gland), ulcerations of the lip and nose, and idiopathic thrombocytopenia. In this sample of young patients, severe headaches were reported in one case. None of the patients suffered from involvement of gastrointestinal organs, respiratory problems, or acute ischemic stroke (AIS).

We assessed a potential association between the number of segments affected by the facial hemangioma (as reported by the patients' child neurologists) and organ involvement (e.g., eyes, brains, and arterial system). As shown in Figure 1, the number of involved organ systems increased significantly with the number of segments affected by facial hemangioma ( $\mathrm{rho}=0.755 ; p=0.011$ ).

\section{Feeding, Sensory Organs, and Development}

Table 3 gives an overview of the patients' impairment, course of disease, and use of supportive therapies. Many caregivers reported feeding difficulties as infants $(n=5)$, the reasons ranging from ulceration of perioral hemangioma to suckling difficulties. However, none of these difficulties were persistent or severe as none required a feeding tube, and none had failure to thrive. Speech development was normal in all cases but one. Multiple patients received physical therapy $(n=4)$, and one additionally had occupational therapy. Slight developmental delay was documented in 1 case, but none required early supportive measures. None of our patients suffered from seizures, and none required neurosurgery. Hearing problems were described in 2 cases, probably due to multiple ear infections. Ophthalmologic symptoms were relatively frequent in this cohort $(n=5)$ and comprised (1) 1 case of amblyopia and ptosis contralateral to facial hemangioma, ipsilateral to intraorbital hemangioma; (2) 1 case of coloboma and optic nerve atrophy resulting in reduced visual acuity, (3) 1 case of increased intraocular pressure, and $(4,5) 2$ cases of transient limitations to open the eye due to periocular hemangioma.

\section{Therapy and Therapeutic Outcome}

As a treatment for facial hemangioma, all patients were administered oral propranolol. Treatment was usually initiated within the first 1.5 months of life. In 2 cases, propranolol was first given at the age of 3 months and 1.0 years, respectively. All cases but one reported good success of hemangioma treatment, and one indicated moderate success (late treatment start was not associated with a worse outcome in this cohort). Usually, a dosage of $2 \mathrm{mg} /$ $\mathrm{kg}$ was used. One case received additional laser therapy. None of the patients required antiepileptic drugs or neurosurgery. Two patients required surgical correction of aortic coarctation. 
Table 3. Impairment, course of disease, and use of supportive therapies

\begin{tabular}{|c|c|}
\hline Patient characteristics $(n=10)$ & $N(\%)$ \\
\hline \multicolumn{2}{|l|}{ Feeding } \\
\hline Any feeding difficulties as infant & $5(50)$ \\
\hline Required tube feeding & $0(0)$ \\
\hline Failure to thrive & $0(0)$ \\
\hline $\begin{array}{l}\text { Age (months) when child drinks liquids from a } \\
\quad \text { cup (mean, SD; not reported } n=4)\end{array}$ & $11.2(4.5)$ \\
\hline \multicolumn{2}{|l|}{ Ophthalmologic symptoms } \\
\hline External, due to facial hemangioma & $2(20)$ \\
\hline Other malformations & $3(30)$ \\
\hline \multicolumn{2}{|l|}{ Hearing problems } \\
\hline Normal newborn hearing screening & $9(90)$ \\
\hline Multiple ear infections or "glue" ear & $2(20)$ \\
\hline Sensorineural hearing loss & $0(0)$ \\
\hline \multicolumn{2}{|l|}{ Speech development } \\
\hline Any delay & $1(10)$ \\
\hline Age (months) when child starts to babble & $1(10)$ \\
\hline Difficulties to understand spoken language & $\begin{array}{l}0(1.5) \\
1(10)\end{array}$ \\
\hline Speech was/is hard to understand & $1(10)$ \\
\hline Seizures & $0(0)$ \\
\hline \multicolumn{2}{|l|}{ Supportive therapies } \\
\hline Early supportive measures & $0(0)$ \\
\hline Physical therapy & $4 / 10(40)$ \\
\hline Occupational therapy & $1 / 10(10)$ \\
\hline Special education services & $0(0)$ \\
\hline Speech and language therapy (not reported $n=1$ ) & $0(0)$ \\
\hline Headaches/Migraine & $1(10)$ \\
\hline
\end{tabular}

Absolute and relative frequencies are indicated for categorical variables. For numerical variables, depending on data distribution, mean and standard deviation, or median and interquartile ranges are indicated.

\section{Discussion/Conclusion}

To the best of our knowledge, this is the first study to provide systematic data on PHACE syndrome in Europe, including Germany, Switzerland, and Austria. We calculated prevalence rates, based on 19 patients identified by systematic acquisition through an email-based network of child neurologists. Assessment of clinical features as well as data on diagnostic and therapeutic procedures was based on 10 patients (52.6\%) of our study cohort who sent back complete questionnaires.

\section{Discussion of Prevalence Rates}

Substantial differences in the prevalence rates were seen between Switzerland (approx. 10-fold higher prevalence rate) on one hand and Austria and Germany on the other hand. This was most likely caused by differences in diagnosis, treatment and follow-up of patients as well as by differences in the administrative infrastructure for patients with PHACE syndrome between the 3 countries. Although we used a well-established network for rare neurologic disorders, underreporting has to be taken into consideration. It may be caused by both "diagnostic bias" as well as "reporting bias": While undiagnosed cases escape every reporting system, bias due to nonreported cases may be discerned using the Capture-Recapture method [19]. In another well-established German Surveillance Tool for rare diseases, ESPED ("Erhebungseinheit für Seltene Pädiatrische Erkrankungen in Deutschland"), completeness of registration for this nonmandatory reporting system has been evaluated and yielded completeness rates between 60 and $70 \%$ for childhood diabetes mellitus [20] and $25 \%$ for children hospitalized due to infection with pertussis [21]. Using the "Capture-Recapture" method, an underreporting rate due to "reporting bias" of $56 \%$ has been calculated for multiple sclerosis in children and adolescents [22]. However, this method requires a second, independent data source - which was not available in our study for PHACE syndrome. As a last aspect, the increasing number of publications on PHACE syndrome in the past decade (e.g., in Pubmed) makes it plausible that awareness of physicians for this rare phacomatosis has increased, probably leading to an increase in the number of diagnosed cases. This may explain the lower prevalence rate in the Orphanet report (last update 2007).

\section{Demographic Features}

The median age in our cohort was 2.5 years, and we found a strong female preponderance of $90 \%$, findings that are compatible with previous reports $[9,23-26]$ : An identical female-to-male ratio of 9:1 had been observed in one of the early PHACE Syndrome Patient Registry reports [26], and another smaller cohort was composed only of females [23]. The proportion of females in larger PHACE cohorts varied between $80.3 \%$ [9] and 88\% [24]. The only male patient of our cohort showed rather severe involvement with extensive facial hemangioma, several cerebrovascular malformations, speech delay, and articulation difficulties as a toddler. Still, previous investigations have shown no hint toward X-linked inheritance as indicated by a study on X-chromosome inactivation patterns [27] or toward differences in prenatal history between the sexes [9]. To date, the reasons for female predominance in PHACE syndrome remain to be elucidated. Regarding ethnicity, this cohort and previous reports indicate that PHACE syndrome is most prevalent in Cau- 
casians $[3,9]$ while other races are less commonly affected.

Cerebrovascular involvement is known to be the most common extracutaneous anomaly in PHACE syndrome [3]. In a prospective multicenter cohort study in 108 patients with large facial hemangiomas including 33 infants with PHACE syndrome, the prevalence of cerebrovascular anomalies was 91\% [3]. A case series and review of 115 PHACE cases detected cerebral vascular anomalies [25] in $77.4 \%$ of the cases. Due to recruitment of our cohort via a network of child neurologists, one could have suspected an increased rate of malformations of the cerebral vasculature, but the rate was $80 \%$ and it is thus in line with previous reports which indicates that no recruitment bias was introduced. Cerebrovascular anomalies described in PHACE syndrome include a wide range of arterial malformations such as dysplasia, hypoplasia, or aplasia of cerebral arteries; stenosis or occlusion of the cerebral arteries; aberrant origin or course of the cerebral arteries; and persistence of embryonic arteries [3]. PHACE syndrome with abnormalities of cardiovascular and cerebral arteries poses an elevated risk for acute stroke. While no acute neurologic events were recorded in our cohort, a review of 22 pediatric patients [28] with PHACE syndrome and AIS showed that aplasia, hypoplasia, or occlusion of at least 1 cerebral artery, additional aortic arch anomalies, and medication with corticosteroids were major risk factors. Notably, all patients with PHACE syndrome and AIS who reported their medication exposure (i.e., $64 \%$ of this cohort) had been treated with corticosteroids [28]. According to current guidelines, due to potential side effects, systemic corticosteroids are only applied in emergencies or refractory situations, for example, respiratory distress in airway hemangioma (see below) [29]. Counseling of caregivers and medical staff of patients with PHACE syndrome with regard to typical symptoms of AIS (new hemiparesis and new seizures) [28] and unspecific symptoms of AIS (irritability and lethargy) [30] may be beneficial. Prothrombotic laboratory workup was positive in only a single patient from 2 published case series of patients with PHACE syndrome and AIS [28, 31], making concomitant coagulopathies in PHACE syndrome unlikely. Following recommendations by an expert panel, antiplatelet prophylaxis with acetylsalicylic acid (4-5 mg/kg) should be considered in asymptomatic high-risk patients [32], and - under careful monitoring for signs of bleeding it has been used successfully following acute stroke in a small case series of infants with PHACE syndrome [31].

Cardiovascular malformations include anomalies of the heart, aorta, and brachiocephalic vessels. The largest study in PHACE patients which investigated cardiovascular anomalies comprised 150 patients from the International PHACE Syndrome Registry and reported $41 \%$ of PHACE cases to be affected [33]. In a smaller study including infants with large facial hemangioma, 67\% of PHACE patients showed any cardiovascular anomaly [3]. Thus, 50\% cardiovascular anomalies in our cohort are in line with data from the literature. As also reflected in our cohort, aortic coarctation is frequent in PHACE syndrome and often necessitates interventional or surgical repair. Bayer et al. [33] identified distinct patterns with regard to aortic coarctation location and histopathologic features in patients with PHACE syndrome; these findings point toward unique etiopathologies when compared to classic aortic coarctation. The high rate of cardiovascular malformation underpins the importance of thorough imaging studies in patients evaluated for PHACE syndrome.

Few studies have addressed neurologic symptoms and sequelae as well as the need for medical supportive measures in children with PHACE syndrome. While the prevalence of developmental delays is unclear, various anomalies have been reported: gross and fine motor delays [34], speech and language delays, [18, 34], dysphagia [35], and early-onset migrainous headaches [36]. In our cohort, as many as $50 \%$ of all cases reported feeding difficulties as an infant, but none required the use of a feeding tube and none had failure to thrive. Speech and language delays were reported rarely in our cohort, yet this may be due to the young age of the included patients (median age: 2.5 years). Many patients of our cohort required physical therapy, a finding compatible with (usually mild) gross motor developmental delays reported previously [34]. To summarize, close clinical/neurologic follow-up including monitoring of nutritional status is important in all patients with PHACE syndrome.

Segmental facial hemangioma, the hallmark in PHACE syndrome, contributes to the patients' morbidity but may also be life-threatening, for example, in airway hemangioma. Potential local complications of facial hemangioma include ulcerations with bleeding, amblyopia in cases blocking the visual axis, and feeding difficulties in perioral hemangioma. Laryngoscopic and bronchoscopic evaluation to rule out airway hemangioma is recommended in every patient with respiratory symptoms or extensive facial hemangioma in the beard localization $[2$, 37]. In the past, different types of treatment for large facial hemangioma have been recorded in PHACE syndrome, including systemic steroids and $\beta$-blockers such as propranolol, interferons, and vincristine [3]. According to a 
common national German guideline by dermatologists, pediatric surgeons, pediatricians, pediatric dermatologists, and oral- and maxillofacial surgeons on the management of infantile hemangioma, use of interferons and vincristine in infantile hemangioma should be abandoned due to severe potential side effects [29]. Systemic steroids may only be used in life-threatening or refractory situations and should be applied for 14 days maximum [29]. In our cohort, oral propranolol (usually $2 \mathrm{mg} /$ $\mathrm{kg}$ ) proved effective - as judged by caregivers - in treatment of facial hemangioma.

We acknowledge a few limitations to our study: First, its retrospective design may have led to recall bias. Yet, the patients' young age and administration of questionnaires to caregivers and to child neurologists should remedy this. Second, the small number of cases results in limited power and increases the likelihood for spurious associations. Moreover, only 10 of 19 patients with PHACE syndrome consented to provide full clinical data for further analysis. Substantial differences in prevalence rates between Switzerland and Germany and Austria were seen, most likely caused by systematic underreporting in Germany and Austria. Nevertheless, results from our cohort are in line with findings from the literature, indicating that our data are nonbiased and that they are representative of the "true" general pediatric PHACE syndrome population.

\section{Conclusions}

To our knowledge, our study is the first to report prevalence rates of PHACE syndrome in Europe, demonstrating that PHACE syndrome is more prevalent than previous reports have indicated. Our data highlight the wide clinical spectrum of PHACE syndrome and show that affected patients require management by a multidisci- plinary team. The clinical observation of an association between the size of facial hemangioma and extent of organ involvement warrants further investigation.

\section{Appendix}

Questionnaires as used in this study: Translated and modified versions of questionnaires originally developed by the International PHACE Registry and Repository (families' version and physicians' version): see online supplementary material (www. karger.com/doi/10.1159/000508187).

\section{Statement of Ethics}

The subjects (or their parents or guardians) have given their written informed consent. The study protocol has been approved by the responsible Institutional Review Board.

\section{Disclosure Statement}

The authors have no conflicts of interest to declare.

\section{Funding Sources}

The authors did not receive any funding.

\section{Author Contributions}

Study idea: S.D. Study design: S.D. and S.M. Data acquisition: S.P.T., M.T., L.W., P.B., C.L., and I.S. Coordination of child neurologists' network for data acquisition: S.S. and K.B. Design of questionnaires: D.S. (major contributor), translation/modification by S.D. Statistical analysis: S.D. Drafting of the manuscript: S.D. Study supervision: S.M. Critical revision of the manuscript for important intellectual content: all authors.

\section{References}

1 Frieden IJ, Reese V, Cohen D. PHACE syndrome. The association of posterior fossa brain malformations, hemangiomas, arterial anomalies, coarctation of the aorta and cardiac defects, and eye abnormalities. Arch Dermatol. 1996 Mar;132(3):307-11.

2 Winter PR, Itinteang T, Leadbitter P, Tan ST. PHACE syndrome - clinical features, aetiology, and management. Acta Paediatr. 2016 Feb;105(2):145-53.
3 Haggstrom AN, Garzon MC, Baselga E, Chamlin SL, Frieden IJ, Holland K, et al. Risk for PHACE syndrome in infants with large facial hemangiomas. Pediatrics. 2010 Aug; 126(2):e418-26.

4 Alvarez H, Lasjaunias P. PHACE-Syndrome (ORPHA 42775). 2007.

5 Brockmann K. Erhebung seltener neurologischer Erkrankungen im Kindesalter. Neuropediatrics. 2014;45:fp036.
6 Orphanet. The portal for rare diseases and orphan drugs. J Pharmacol Pharmacother. 2020;4(2):168-9.

7 Disse SC, Zemlin M, Mueller C, Meyer S. PHACE syndrome-before and after propranolol therapy. J Pediatr. 2018 Feb;193:275.

8 Metry D, Heyer G, Hess C, Garzon M, Haggstrom A, Frommelt P, et al. Consensus statement on diagnostic criteria for PHACE syndrome. Pediatrics. 2009 Nov;124(5):144756. 
9 Wan J, Steiner J, Baselga E, Blei F, Cordisco $\mathrm{M}$, Garzon MC, et al. Prenatal risk factors for PHACE syndrome: a study using the PHACE Syndrome International Clinical Registry and Genetic Repository. J Pediatr. 2017 Nov; 190:275-9.

10 Forum on Child and Family Statistics. America's children: key national indicators of wellbeing, 2019. America's children: key national indicators of well-being. 2019-2020. Available from: https://www.childstats.gov/pubs/.

11 Statistics Canada. Table 39-10-0041-01. Census families with children by age of children and children by age groups. Government of Canada; 2020.

12 Bundesamt für Statistik. Ständige Wohnbevölkerung nach Alter, Kanton, Bezirk und Gemeinde, 2010-2017. 2018, August 31st.

13 Bundesamt für Statistik. Ständige Wohnbevölkerung in der Schweiz nach Alter und Geschlecht am 31. Dezember 2018. 2019.

14 Bevölkerung - Zahl der Einwohner in Deutschland nach Altersgruppen am 31. Dezember 2017 (in Millionen). 2019.

15 (Destatis) SB. Bevölkerung: Deutschland, Stichtag, Altersjahre. Statistisches Bundesamt (Destatis); 2019.

16 Bundesamt für Statistik. Zeit, Wohnbevölkerung im Jahresdurchschnitt und Alter in 15-Jahresgruppen nach Geschlecht. 2019.

17 Flanders WD, Kleinbaum DG. Basic models for disease occurrence in epidemiology. Int $\mathrm{J}$ Epidemiol. 1995 Feb;24(1):1-7.

18 Martin KL, Arvedson JC, Bayer ML, Drolet BA, Chun R, Siegel DH. Risk of dysphagia and speech and language delay in PHACE syndrome. Pediatr Dermatol. 2015 Jan-Feb; 32(1):64-9.

19 Brenner H. Use and limitations of the capture-recapture method in disease monitoring with two dependent sources. Epidemiology. 1995 Jan;6(1):42-8

20 Rosenbauer J, Herzig P, von Kries R, Neu A, Giani G. Temporal, seasonal, and geographical incidence patterns of type I diabetes mellitus in children under 5 years of age in Germany. Diabetologia. 1999 Sep;42(9):1055-9.
21 Schielke A, Takla A, von Kries R, Wichmann $\mathrm{O}$, Hellenbrand W. Marked under-reporting of pertussis requiring hospitalization in infants as estimated by capture-recapture methodology, Germany, 2013-2015. Pediatr Infect Dis J. 2018 Feb;37(2):119-25.

22 Ebrahimi-Fakhari D, Zemlin M, Sauer H, Poryo M, Graf N, Meyer S. [25 years of ESPED as a surveillance tool for rare diseases in children in Germany: a critical analysis]. Klin Padiatr. 2018 Jul;230(4):215-24.

23 Metry DW, Dowd CF, Barkovich AJ, Frieden IJ. The many faces of PHACE syndrome. J Pediatr. 2001 Jul;139(1):117-23.

24 Metry DW, Haggstrom AN, Drolet BA, Baselga E, Chamlin S, Garzon M, et al. A prospective study of PHACE syndrome in infantile hemangiomas: demographic features, clinical findings, and complications. Am J Med Genet A. 2006 May 1;140(9):975-86.

25 Heyer GL, Dowling MM, Licht DJ, Tay SK, Morel K, Garzon MC, et al. The cerebral vasculopathy of PHACES syndrome. Stroke. $2008 \mathrm{Feb} ; 39(2): 308-16$.

26 Metry DW, Garzon MC, Drolet BA, From melt P, Haggstrom A, Hall J, et al. PHACE syndrome: current knowledge, future directions. Pediatr Dermatol. 2009 Jul-Aug; 26(4):381-98.

27 Sullivan CT, Christian SL, Shieh JT, Metry D, Blei F, Krol A, et al. X chromosome-inactivation patterns in 31 individuals with PHACE syndrome. Mol Syndromol. 2013 Mar; 4(3):114-8.

28 Siegel DH, Tefft KA, Kelly T, Johnson C, Metry D, Burrows $\mathrm{P}$, et al. Stroke in children with posterior fossa brain malformations, hemangiomas, arterial anomalies, coarctation of the aorta and cardiac defects, and eye abnormalities (PHACE) syndrome: a systematic review of the literature. Stroke. 2012 Jun;43 (6):1672-4.
29 AWMF. Infantile Hämangiome im Säuglings- und Kleinkindesalter. Deutsche Gesellschaft für Kinderchirurgie, Deutschen Gesellschaft für Kinder- und Jugendmedizin, Deutsche Dermatologische Gesellschaft, Arbeitsgemeinschaft Pädiatrische Dermatologie und die Deutsche Gesellschaft für Mund-, Kiefer- und Gesichtschirurgie; 2015.

30 Rajani NK, Pearce K, Campion T, Salpietro V, Planells M, Chong W, et al. Pediatric stroke: current diagnostic and management challenges. Quant Imag Med Surg. 2018 Nov; 8(10):984-91.

31 Drolet BA, Dohil M, Golomb MR, Wells R, Murowski L, Tamburro J, et al. Early stroke and cerebral vasculopathy in children with facial hemangiomas and PHACE association. Pediatrics. 2006 Mar;117(3):959-64.

32 Garzon MC, Epstein LG, Heyer GL, Frommelt PC, Orbach DB, Baylis AL, et al. PHACE syndrome: consensus-derived diagnosis and care recommendations. J Pediatr. 2016 Nov; 178:24-e2.

33 Bayer ML, Frommelt PC, Blei F, Breur JM, Cordisco MR, Frieden IJ, et al. Congenital cardiac, aortic arch, and vascular bed anomalies in PHACE syndrome (from the International PHACE Syndrome Registry). Am J Cardiol. 2013 Dec 15;112(12):1948-52.

34 Tangtiphaiboontana J, Hess CP, Bayer M, Drolet BA, Nassif LM, Metry DW, et al. Neurodevelopmental abnormalities in children with PHACE syndrome. J Child Neurol. 2013 May;28(5):608-14.

35 Pascual-Castroviejo I, Pascual-Pascual SI, Velázquez-Fragua R, García L, López-Gutiérrez JC, Viaño-López J, et al. [Cutaneous hemangiomas and vascular malformations and associated pathology (Pascual-Castroviejo type II syndrome). Study of 41 patients]. Rev Neurol. 2005 Aug 16-31;41(4):223-36.

$36 \mathrm{Yu}$ J, Siegel DH, Drolet BA, Blei F, Epstein LG, Metry D, et al. Prevalence and clinical characteristics of headaches in PHACE syndrome. J Child Neurol. 2016 Mar;31(4):468-73.

37 Durr ML, Meyer AK, Huoh KC, Frieden IJ, Rosbe KW. Airway hemangiomas in PHACE syndrome. Laryngoscope. 2012; 122(10):2323-9. 